\title{
Update on Pancreatobiliary Stents: Stent Placement in Advanced Hilar Tumors
}

\author{
Sung III Jang' and Dong Ki Lee ${ }^{2}$ \\ ${ }^{1}$ Department of Internal Medicine, Hallym University Kangnam Sacred Heart Hospital, Hallym University College of Medicine, Seoul, ${ }^{2}$ Department of \\ Internal Medicine, Gangnam Severance Hospital, Yonsei University College of Medicine, Seoul, Korea
}

Palliative drainage is the main treatment option for inoperable hilar cholangiocarcinoma to improve symptoms, which include cholangitis, pruritus, high-grade jaundice, and abdominal pain. Although there is no consensus on the optimal method for biliary drainage due to the paucity of large-scale randomized control studies, several important aspects of any optimal method have been studied. In this review article, we discuss the liver volume to be drained, stent type, techniques to insert self-expanding metal stents, and approaches for proper and effective biliary drainage based on previous studies and personal experience.

Key Words: Hilar cholangiocarcinoma; Cholangiocarcinoma; Klatskin’s tumor; Palliation; Biliary stenting

\section{INTRODUCTION}

Hilar cholangiocarcinoma (HCCA) is the most common type of bile duct cancer, accounting for $46 \%$ to $97 \%$ of all bile duct cancers. ${ }^{1,2}$ Surgical resection is only possible in $20 \%$ to $30 \%$ of patients with HCCA. Therefore, palliative bile drainage intervention is required for patients with unresectable HCCA. The three established methods used for palliation of HCCA are endoscopic drainage, percutaneous drainage, and surgical bypass. However, there is a lack of well-designed comparative or randomized studies regarding the optimal method. Although the Asia-Pacific Working Group on Hepatobiliary Cancer recently made several recommendations, ${ }^{1}$ establishing a consensus regarding palliation of HCCA remains a challenge. In this review, we describe several points of concern for biliary drainage in HCCA based on evidence and personal experience, and discuss the palliative drainage methods for advanced HCCA, mostly for patients with higher than Bismuth type

Received: April 10, 2015 Revised: May 11, 2015

Accepted: May 11, 2015

Correspondence: Dong Ki Lee

Department of Internal Medicine, Gangnam Severance Hospital, Yonsei University College of Medicine, 211 Eonju-ro, Gangnam-gu, Seoul 135-720, Korea Tel: +82-2-2019-3214, Fax: +82-2-3463-3882, E-mail: dklee@yuhs.ac

(c) This is an Open Access article distributed under the terms of the Creative Commons Attribution Non-Commercial License (http://creativecommons.org/ licenses/by-nc/3.0) which permits unrestricted non-commercial use, distribution, and reproduction in any medium, provided the original work is properly cited.
III HCCA.

\section{HOW MUCH OF THE LIVER SHOULD BE DRAINED IN A PATIENT WITH HCCA AND IS MULTISECTORIAL DRAINAGE NECESSARY?}

The right, left, and caudate lobes of the liver occupy approximately $55 \%$ to $60 \%, 30 \%$ to $35 \%$, and $10 \%$ of the liver volume, respectively. ${ }^{3}$ One study showed that only $25 \%$ of the liver volume can be drained for palliation of jaundice not accompanied by cholangitis. ${ }^{4}$ However, another study reported a greater decrease in bilirubin level, lower incidence of early cholangitis, and longer patient survival when $>50 \%$ of the liver volume was drained, compared to draining $<50 \%{ }^{5}$ The Asia-Pacific Working Group on Hepatobiliary Cancer also recommends draining $>50 \%$ of the liver volume. ${ }^{1}$

A close relationship between drained liver volume and the number of stents has been identified. Increased bilateral, rather than unilateral, stenting is required to increase drained liver volume. A single stent alone can drain both lobes in a patient with Bismuth type I HCCA, but draining patients with Bismuth types II to IV requires multiple stents. Unilateral stenting has a high technical success rate for stent placement and low early complication rates. ${ }^{6}$ However, there is a limitation on sufficient drainage $>50 \%$ of liver volume for patients with Bis- 
muth type II and higher. Additionally, if an infected bile duct cannot be drained, the risk of cholangitis and liver abscess may increase (Fig. 1). In contrast, bilateral stenting preserves functional liver volume, lowers the risk of cholangitis, and reduces complications by draining the infected duct when there is inflammation in a bilateral infected duct, extending patient survival (Table 1). ${ }^{7-14}$

Injecting contrast dye into undrained ducts can increase the incidence of postprocedural cholangitis and lower the survival rate. ${ }^{15}$ Preoperative staging and procedural planning with noninvasive imaging, such as magnetic resonance cholangiography (MRCP) or computed tomography (CT), are important in lowering the risk of cholangitis by unsuccessful endoscopy. ${ }^{16-20}$ These imaging techniques prevent inadvertent injection of contrast into atrophied or multiple unintended hepatic segments. Furthermore, selectively targeted and planned drainage lowers the risk of cholangitis or septicemia by identifying the inflamed bile duct. Therefore, excluding an atrophied segment of lobe or segment and effectively draining the dominant liver lobe lowers the risk of cholangitis and extends patient survival. These benefits arising from bilateral drainage with metallic stents are technically achievable with appropriate endoscopic expertise, development of metal stents, and higher technical and functional success rates, even in patients with Bismuth types III or IV. $^{21-29}$ Thus, the number of biliary stents inserted for palliation and drained liver segments in patients with HCCA must be determined based on the extent of malignant biliary strictures observed on pre-procedural imaging and the degree of biliary tract contamination during biliary drainage.

\section{SELF-EXPANDING METAL STENTS ARE BETTER THAN PLASTIC STENTS FOR ADVANCED HCCA}

The types of stents used for palliation in HCCA include plastic stents (PSs) and uncovered self-expanding metal stents (SEMSs). PS are less expensive and their insertion and removal are technically easier compared to SEMS. However, because the diameter of PS is smaller than that of SEMS (10 to 12 Fr vs. 8 to $10 \mathrm{~mm}$, respectively), PS occlude more rapidly than SEMS and has a shorter median patency time (1.4 to 3 months vs. 6 to 10 months, respectively). ${ }^{30}$ Moreover, insertion of more than
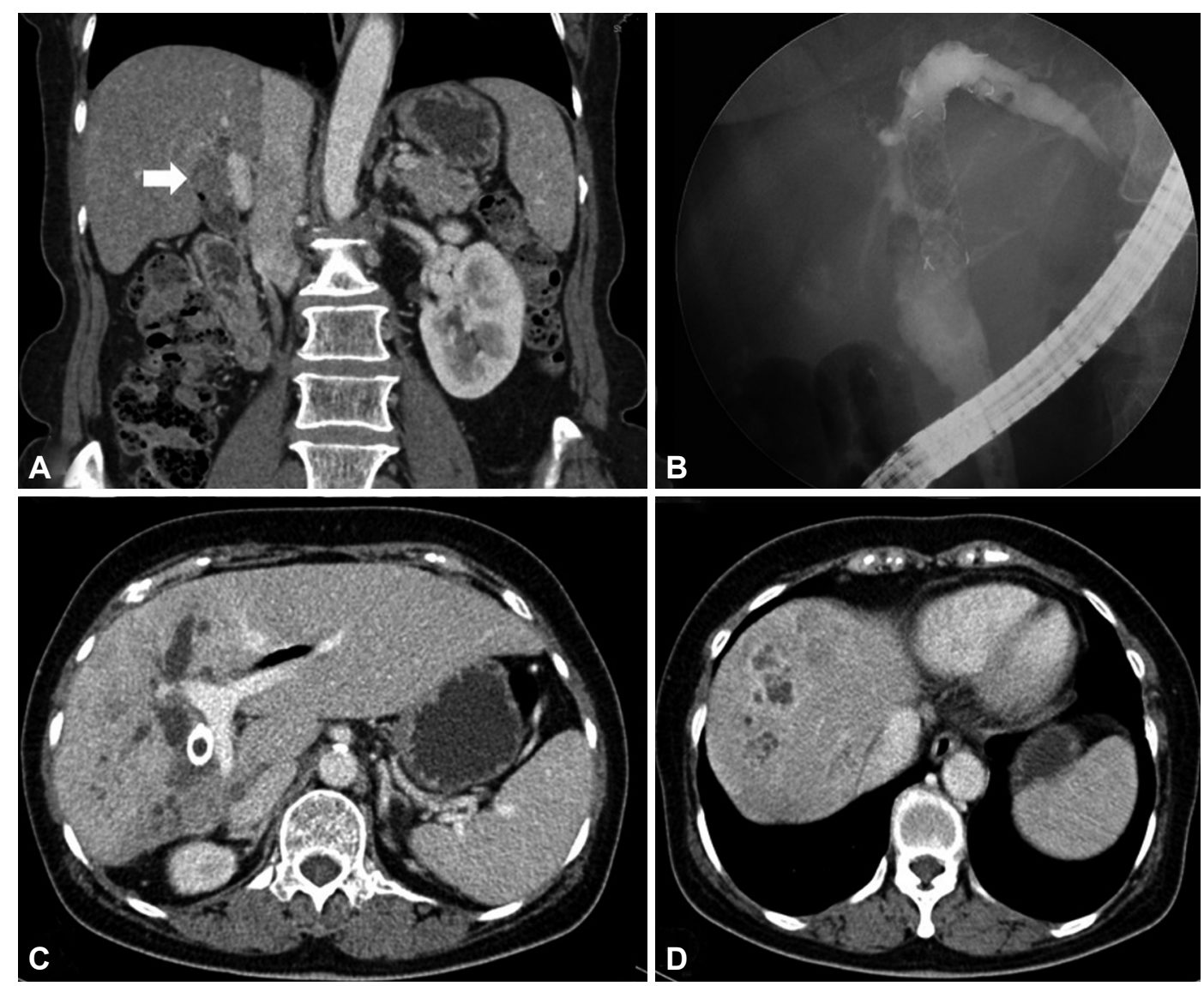

Fig. 1. Formation of a liver abscess after insertion of a unilateral metal stent in a patient with hilar cholangiocarcinoma. (A) Inoperable papillary-type cholangiocarcinoma (white arrow) diagnosed as Bismuth type IV based on the initial computed tomography scan. (B) A self-expandable metal stent was inserted unilaterally in the left lobe via the percutaneous tract after failed endoscopic stenting. (C) The stent was occluded due to tumor in-growth after 8 months. (D) The liver abscess developed in the right lobe, the contralateral side during stent insertion. 


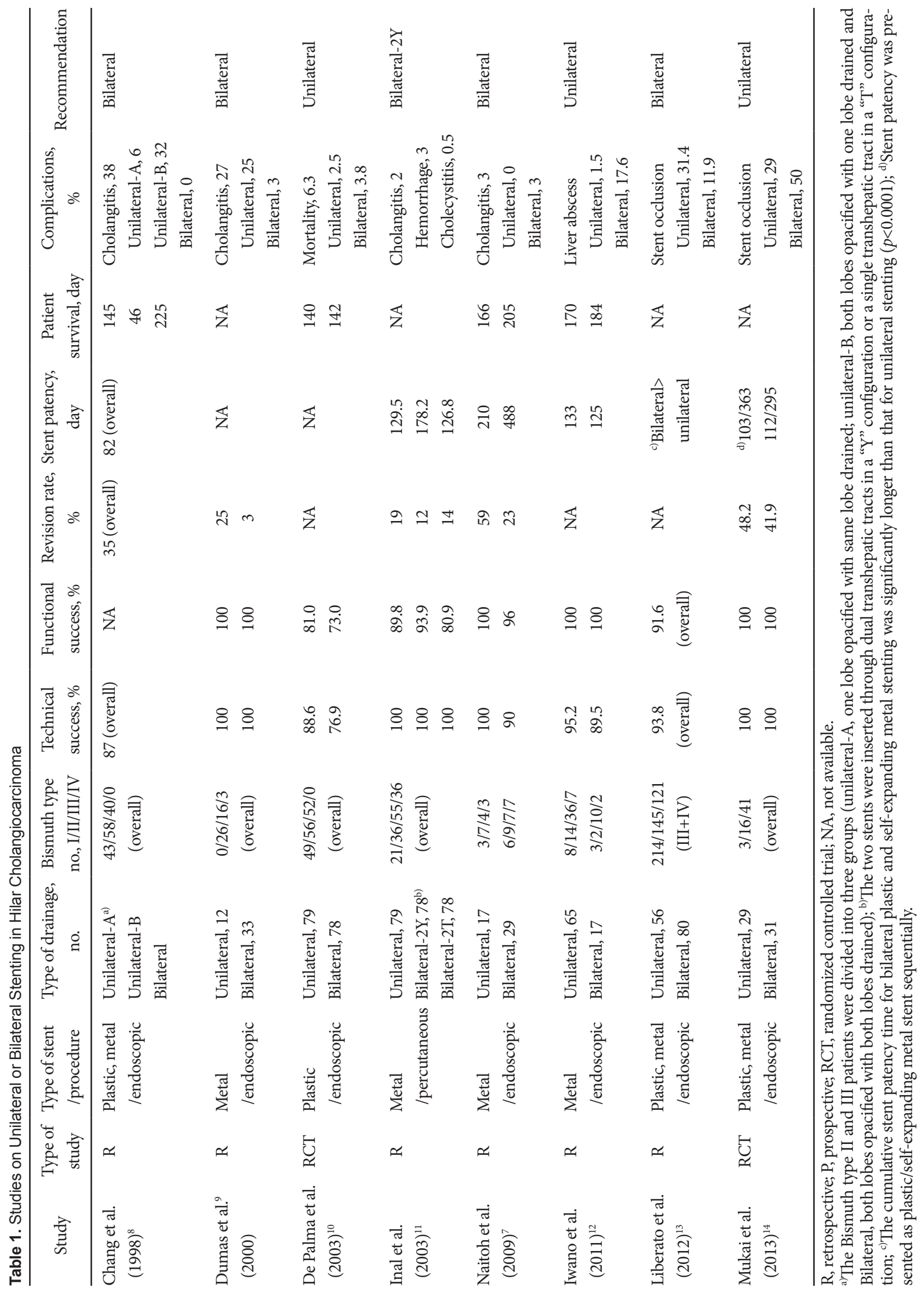


two 10-Fr diameter PS is difficult and can increase migration rates. ${ }^{31,32}$ In contrast, SEMS used for HCCA are uncovered, allowing drainage of side branches. SEMS have superior success rates, minimal adverse effects, fewer requirements for re-intervention, and higher patient survival compared to PS. ${ }^{33}$ Despite the high initial cost, SEMS have superior cost-effectiveness due to the greater success rate, shorter hospital stay, fewer blockages, fewer re-interventions, and lower antibiotic needs compared to PS, when expected patient survival is $>4$ to 6 months (Table 2). ${ }^{34-36}$ The Asia-Pacific Consensus also recommends biliary palliation with SEMS for patients with predicted survival $>3$ months and Bismuth types II to IV HCCA. ${ }^{1}$ However, if biliary drainage is performed when a treatment plan for HCCA has not been definitely determined, PS can be temporarily inserted, as PS are removable while SEMS are not. ${ }^{37}$

\section{INSERTION OF MULTIPLE SEMS: SIDE-BY-SIDE OR STENT-IN-STENT}

There are two methods of insertion of multiple SEMS for HCCA. The "side-by-side" method requires insertion of the first stent in one of the hepatic ducts and insertion of the second stent into the contralateral hepatic duct parallel to the first stent. ${ }^{9,38-40}$ The "stent-in-stent" method requires insertion of the second stent in the contralateral hepatic duct through mesh of the first stent..$^{23,41-46}$ Insertion of a stent in bilateral side-byside stent placement is easier when guidewires are inserted into the right and left hepatic ducts. Endoscopic revision of the stents is also easier on stent occlusion. ${ }^{38}$ However, disadvantages include the potential for interference when inserting the delivery system for the second stent due to resistance from the already inserted first stent and difficulties in aligning the distal ends of the two stents. A simultaneous side-byside deployment method using a thin 6-Fr delivery system was developed to overcome these issues and has shown a high success rate. ${ }^{39}$ However, side-by-side deployment can occlude a portal vein and increase the rate of cholangitis because of excessive expansion of the bile duct by the parallel stents. The excessive expansion force of two deployed SEMS, particularly large-diameter SEMS with a closed metal mesh design, can cause severe pain and vascular injury, possibly leading to massive bleeding.

Effective drainage can be difficult using the side-by-side method in a non-dilated common bile duct and an insufficiently deployed stent can block bile duct flow. Bilateral stent-in-stent deployment is less likely to cause these complications because the stents overlap within the common bile duct. However, it is technically difficult to insert a guidewire for the second stent into the contralateral bile duct through the mesh of the first stent. Moreover, endoscopic revision for an occluded stent is dif-

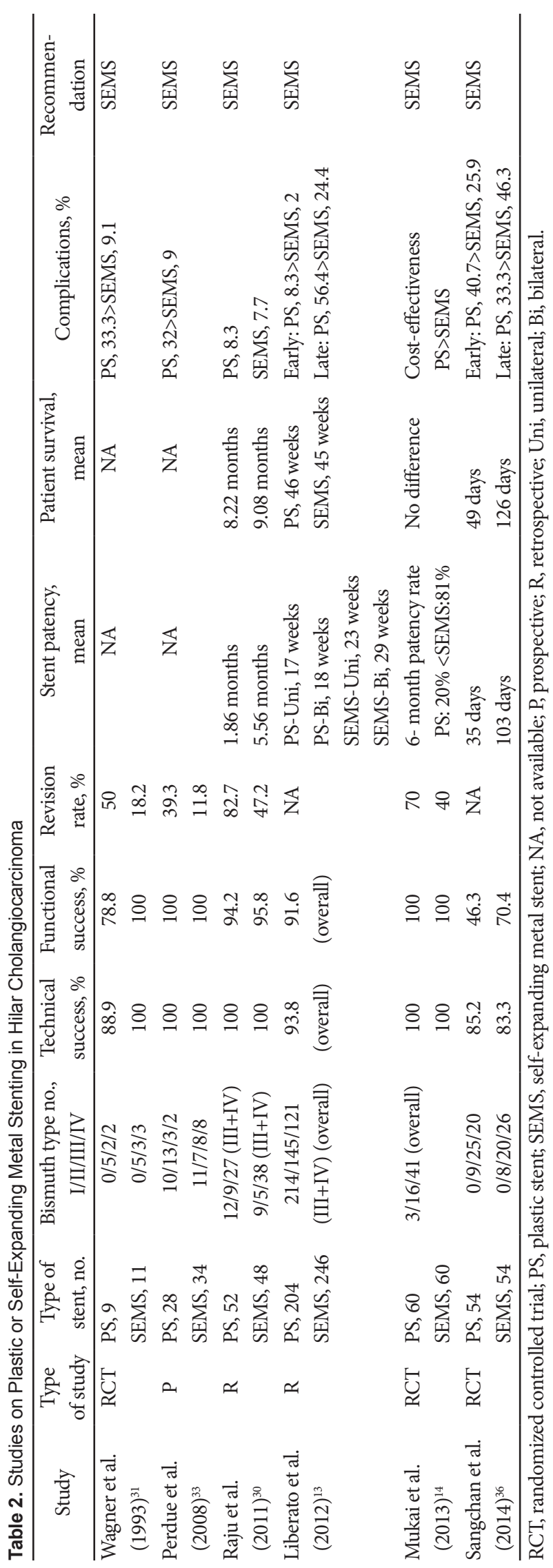


ficult compared to the side-by-side method. Large open-celled wire mesh stents were designed to resolve these issues, using a guidewire to facilitate insertion of the second stent and improve the success rate. This mesh design enables an easy re-intervention. However, the expanding radial force is reduced because of the large cell and susceptibility to tumor in-growth increases.

The success rates for the side-by-side and stent-in-stent methods are $73.3 \%$ to $100 \%$ and $80 \%$ to $100 \%$, respectively. ${ }^{9,38-47}$ Although the incidence of complications is higher for the side-by-side method than the stent-in-stent method, stent patency rates are superior. ${ }^{48}$ No well-designed large-scale comparative studies with long-term follow-up have been performed; therefore, no definite consensus has been reached. Nevertheless, it is expected that attempts to improve the success rate with modifying stents and technical developments of the stent-in-stent method will result in its more frequent use.
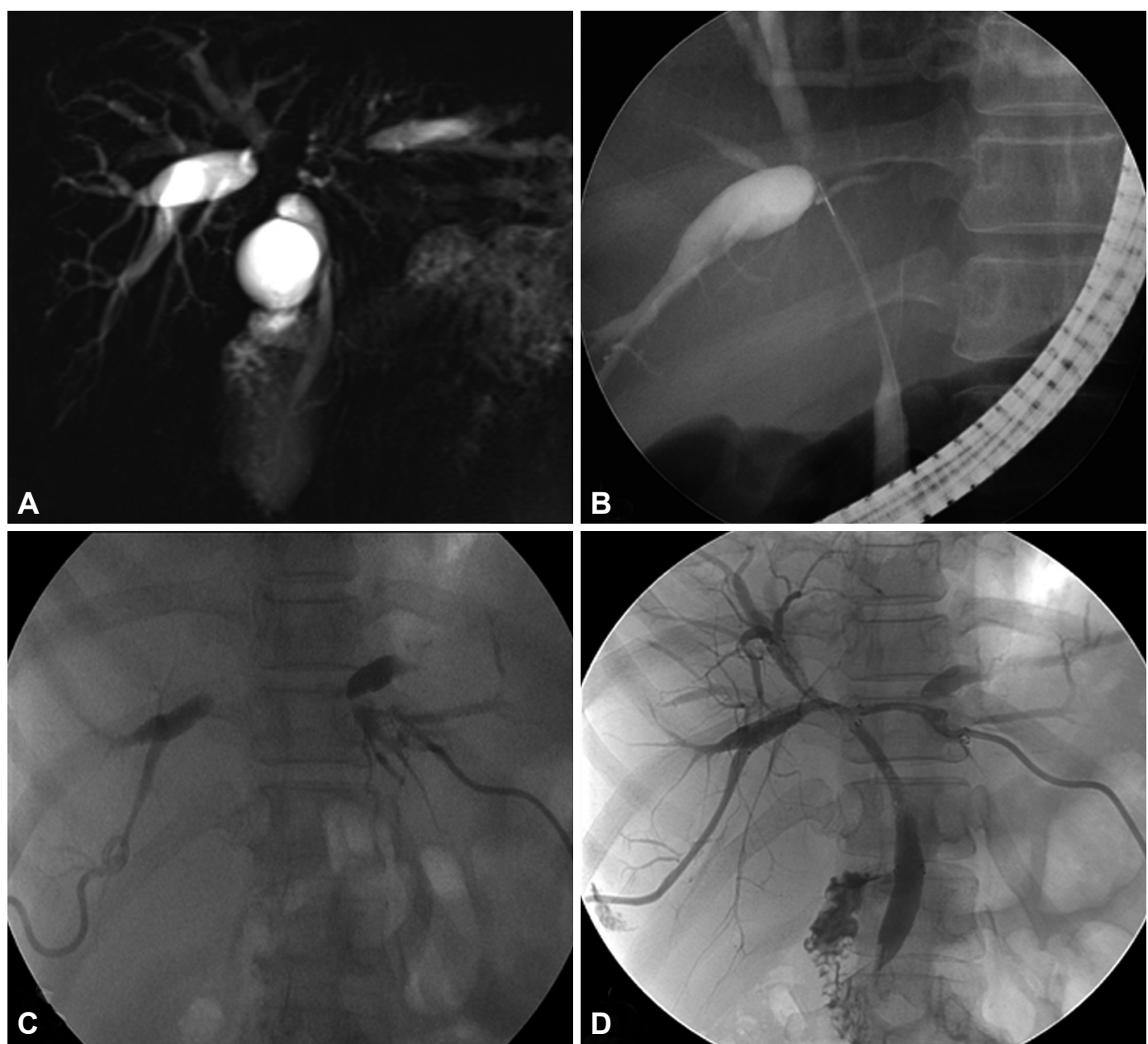

Fig. 2. Cholangiograms demonstrating successful palliation using the percutaneous method after failed endoscopy. (A) Magnetic resonance cholangiography demonstrated a Bismuth type IV hilar malignancy, with dilation of both intrahepatic ducts. (B) The guidewire was not able to pass through the stricture site during endoscopy due to tightness. (C) An ultrasound-guided puncture at both intrahepatic ducts was successful. (D) Two self-expandable metal stents (X-type) were inserted successfully via the previous percutaneous tracts. 
endoscopic retrograde cholangiopancreatography for endoscopic drainage and the high incidence of postprocedural cholangitis, are a problem. A multicenter retrospective study found that percutaneous procedures have significantly higher success rates and a lower risk of cholangitis than endoscopic drainage in patients with advanced HCCA. ${ }^{49}$ Therefore, the Asian-Pacific Consensus recommends that endoscopic palliation be considered as an initial treatment for less-advanced Bismuth types (I and II) and that percutaneous palliation be considered for advanced Bismuth types (III and IV). ${ }^{1}$ However, endoscopy is the initial approach, even in patients with advanced Bismuth types in actual clinical practices at many institutes, including ours. Nevertheless, we prefer to convert endoscopy to a percutaneous approach when any difficulties are encountered during the procedure. This policy is better than a "never give up policy" for patient safety and preventing procedure-related adverse events. Unlike previous studies describing only short-term outcomes, large-scale randomized studies are needed to investigate long-term outcomes regarding the duration of efficient drainage and the possibility of effective re- intervention when a stent becomes obstructed.

\section{WHEN SHOULD WE CALL AN INTERVENTIONAL RADIOLOGIST?}

Drainage is necessary because the complication rate, including postprocedural cholangitis, increases when contrast dye is injected into undrained bile ducts. ${ }^{34}$ Therefore, percutaneous drainage must be performed immediately after unsuccessful endoscopic drainage to prevent postprocedural cholangitis and improve the palliative success rate. ${ }^{49}$ The success rate of palliation is higher in a percutaneous approach in patients with advanced HCCA (Bismuth types III and IV) compared to an endoscopic approach. This is due to: (1) puncture at a precisely selected bile duct; (2) easier guidewire and catheter approach; and (3) a greater variety of designs for drainage (Tor X-shaped). ${ }^{50}$ Our comparative study of patients who underwent successful initial endoscopic SEMS stenting (group I) and patients who underwent unsuccessful initial endoscopic SEMS stenting but successful subsequent percutaneous SEMS
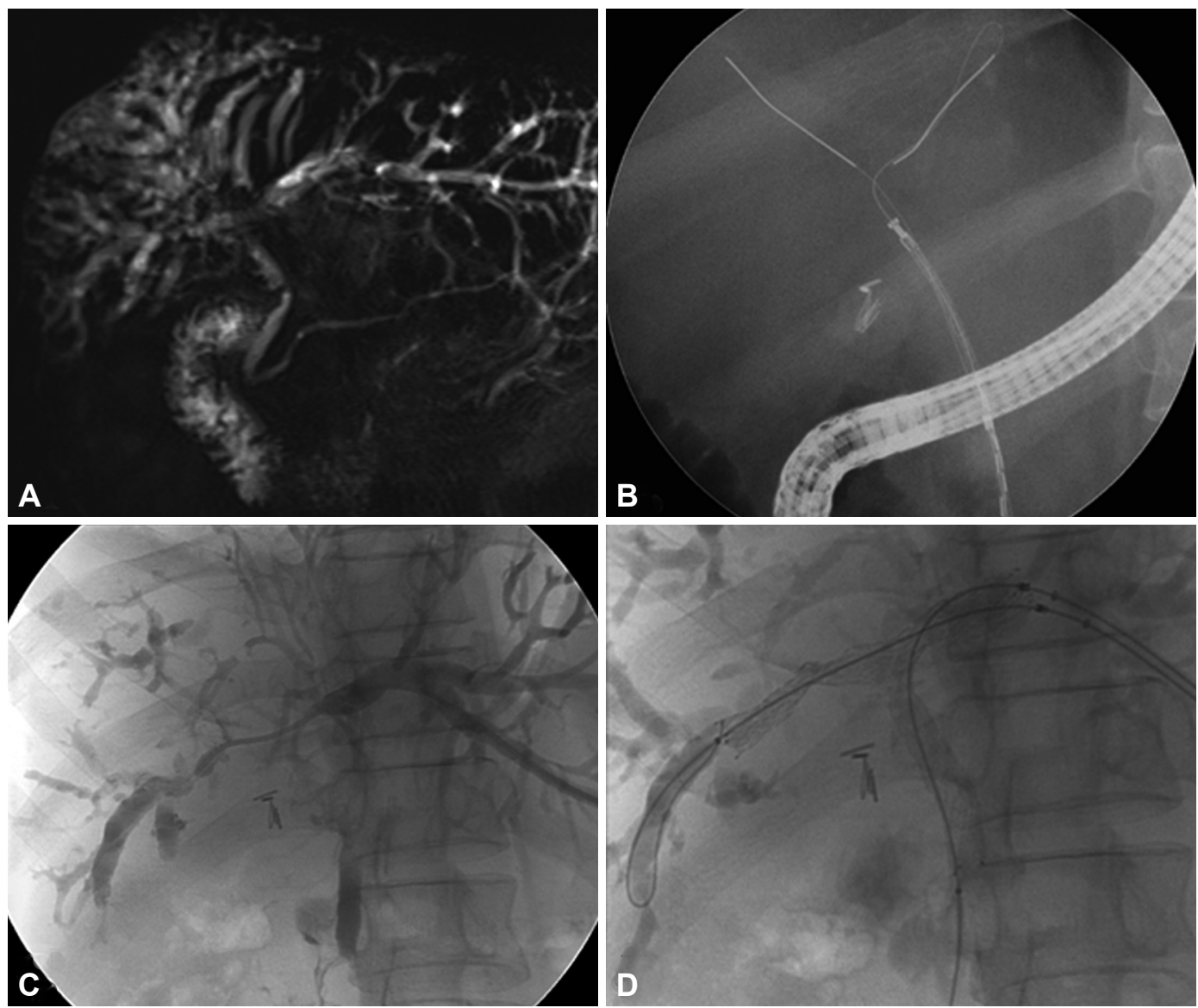

Fig. 3. Cholangiograms demonstrating successful palliation using the percutaneous method after failed endoscopy. (A) Magnetic resonance cholangiography demonstrated a Bismuth type IV hilar malignancy, with dilation of both intrahepatic ducts. (B) Although the guidewire was able to pass through the stricture site, the 8-Fr metal stent delivery system could not be passed during endoscopy due to tightness. (C) An ultrasound-guided puncture in the right intrahepatic duct was successful. (D) Two self-expandable metal stents (T-type) were inserted successfully via the previous percutaneous tract. 
stenting (group II) showed that the success rate of endoscopic stenting for patients with advanced HCCA (Bismuth types III and IV) was lower than that for percutaneous stenting (72.4\% vs. $100 \%$, respectively; $p<0.05$, unpublished data). Importantly, sequential stenting by the percutaneous method was possible for all patients who failed in the endoscopic retrograde method through endoscopic retrograde cholangiopancreatography. Although strictures in these patients were tight and had a long segment preventing the guidewire from being passed in the endoscopic method, the percutaneous anterograde method may overcome these limitations (Figs. 2, 3). These results are similar to previous studies. ${ }^{49}$ Therefore, the percutaneous approach should be considered as initial palliation for some patients with advanced and difficult Bismuth types III and IV HCCA. Moreover, sequential percutaneous intervention is important for successful palliation when an endoscopic approach fails.

\section{CONCLUSIONS}

The top priority for palliation of unresectable HCCA is to determine a drainage plan prior to the procedure using noninvasive imaging, such as MRCP or CT. Moreover, it is important to consider several factors, such as the patient's bile duct, hepatic anatomical information, the patient's condition, existing medical sources, and the endoscopist's expertise, when selecting the appropriate bile duct for drainage, type and number of stents, and drainage method for the most effective palliation. All attempts must be made to drain the infected bile duct, and a percutaneous method should be considered first for patients with advanced HCCA (Bismuth types III and IV). In particular, if the intention to treat initially fails using endoscopy, it is essential to switch immediately to a percutaneous method.

\section{Conflicts of Interest}

The authors have no financial conflicts of interest.

\section{REFERENCES}

1. Rerknimitr R, Angsuwatcharakon P, Ratanachu-ek T, et al. Asia-Pacific consensus recommendations for endoscopic and interventional management of hilar cholangiocarcinoma. J Gastroenterol Hepatol 2013;28: 593-607.

2. Deoliveira ML, Schulick RD, Nimura Y, et al. New staging system and a registry for perihilar cholangiocarcinoma. Hepatology 2011;53:13631371.

3. Bismuth H. Surgical anatomy and anatomical surgery of the liver. World J Surg 1982;6:3-9.

4. Dowsett JF, Vaira D, Hatfield AR, et al. Endoscopic biliary therapy using the combined percutaneous and endoscopic technique. Gastroenterology 1989;96:1180-1186.

5. Vienne A, Hobeika E, Gouya H, et al. Prediction of drainage effectiveness during endoscopic stenting of malignant hilar strictures: the role of liver volume assessment. Gastrointest Endosc 2010;72:728-735.
6. De Palma GD, Galloro G, Siciliano S, Iovino P, Catanzano C. Unilateral versus bilateral endoscopic hepatic duct drainage in patients with malignant hilar biliary obstruction: results of a prospective, randomized, and controlled study. Gastrointest Endosc 2001;53:547-553.

7. Naitoh I, Ohara H, Nakazawa T, et al. Unilateral versus bilateral endoscopic metal stenting for malignant hilar biliary obstruction. J Gastroenterol Hepatol 2009;24:552-557.

8. Chang WH, Kortan P, Haber GB. Outcome in patients with bifurcation tumors who undergo unilateral versus bilateral hepatic duct drainage. Gastrointest Endosc 1998;47:354-362.

9. Dumas R, Demuth N, Buckley M, et al. Endoscopic bilateral metal stent placement for malignant hilar stenoses: identification of optimal technique. Gastrointest Endosc 2000;51:334-338.

10. De Palma GD, Pezzullo A, Rega M, et al. Unilateral placement of metallic stents for malignant hilar obstruction: a prospective study. Gastrointest Endosc 2003;58:50-53.

11. Inal M, Akgül E, Aksungur E, Seydaoğlu G. Percutaneous placement of biliary metallic stents in patients with malignant hilar obstruction: unilobar versus bilobar drainage. J Vasc Interv Radiol 2003;14:1409-1416.

12. Iwano $\mathrm{H}$, Ryozawa $\mathrm{S}$, Ishigaki $\mathrm{N}$, et al. Unilateral versus bilateral drainage using self-expandable metallic stent for unresectable hilar biliary obstruction. Dig Endosc 2011;23:43-48.

13. Liberato MJ, Canena JM. Endoscopic stenting for hilar cholangiocarcinoma: efficacy of unilateral and bilateral placement of plastic and metal stents in a retrospective review of 480 patients. BMC Gastroenterol 2012; 12:103.

14. Mukai T, Yasuda I, Nakashima M, et al. Metallic stents are more efficacious than plastic stents in unresectable malignant hilar biliary strictures: a randomized controlled trial. J Hepatobiliary Pancreat Sci 2013;20:214222.

15. Ertuğrul I, Yüksel I, Parlak E, et al. Risk factors for endoscopic retrograde cholangiopancreatography-related cholangitis: a prospective study. Turk J Gastroenterol 2009;20:116-121.

16. Hanninen EL, Pech M, Jonas S, et al. Magnetic resonance imaging including magnetic resonance cholangiopancreatography for tumor localization and therapy planning in malignant hilar obstructions. Acta Radiol 2005;46:462-470.

17. Freeman ML, Overby C. Selective MRCP and CT-targeted drainage of malignant hilar biliary obstruction with self-expanding metallic stents. Gastrointest Endosc 2003;58:41-49.

18. Lopera JE, Soto JA, Múnera F. Malignant hilar and perihilar biliary obstruction: use of MR cholangiography to define the extent of biliary ductal involvement and plan percutaneous interventions. Radiology 2001; 220:90-96.

19. Masselli G, Manfredi R, Vecchioli A, Gualdi G. MR imaging and MR cholangiopancreatography in the preoperative evaluation of hilar cholangiocarcinoma: correlation with surgical and pathologic findings. Eur Radiol 2008;18:2213-2221.

20. Zidi SH, Prat F, Le Guen O, Rondeau Y, Pelletier G. Performance characteristics of magnetic resonance cholangiography in the staging of malignant hilar strictures. Gut 2000;46:103-106.

21. Bae JI, Park AW, Choi SJ, et al. Crisscross-configured dual stent placement for trisectoral drainage in patients with advanced biliary hilar malignancies. J Vasc Interv Radiol 2008;19:1614-1619.

22. Ridtitid W, Rerknimitr R, Janchai A, Kongkam P, Treeprasertsuk S, Kullavanijaya P. Outcome of second interventions for occluded metallic stents in patients with malignant biliary obstruction. Surg Endosc 2010;24:2216-2220.

23. Kim JY, Kang DH, Kim HW, et al. Usefulness of slimmer and opencell-design stents for endoscopic bilateral stenting and endoscopic revision in patients with hilar cholangiocarcinoma (with video). Gastrointest Endosc 2009;70:1109-1115.

24. Kogure H, Isayama H, Nakai Y, et al. Newly designed large cell Niti-S stent for malignant hilar biliary obstruction: a pilot study. Surg Endosc 2011;25:463-467. 
25. Köklü S, Koçak E, Akbal E. Air cholangiography for severe hilar obstruction at ERCP. Gastrointest Endosc 2011;73:1326.

26. Kato H, Kawamoto H, Noma Y, et al. Dilatation by Soehendra stent retriever is feasible and effective in multiple deployment of metallic stents to malignant hilar biliary strictures. Hepatogastroenterology 2013;60: 286-290.

27. Kim JY, Kang DH, Choi CW, Kim HW, Park SB, Kim DU. Selective intrahepatic duct cannulation by using a triple-lumen catheter for endoscopic bilateral stenting in hilar cholangiocarcinoma. Gastrointest Endosc 2010;72:192-198.

28. Pisello F, Geraci G, Modica G, Sciumè C. Cholangitis prevention in endoscopic Klatskin tumor palliation: air cholangiography technique. Langenbecks Arch Surg 2009;394:1109-1114.

29. Sud R, Puri R, Choudhary NS, Mehta A, Jain PK. Air cholangiogram is not inferior to dye cholangiogram for malignant hilar biliary obstruction: a randomized study of efficacy and safety. Indian J Gastroenterol 2014;33:537-542.

30. Raju RP, Jaganmohan SR, Ross WA, et al. Optimum palliation of inoperable hilar cholangiocarcinoma: comparative assessment of the efficacy of plastic and self-expanding metal stents. Dig Dis Sci 2011;56:1557-1564.

31. Wagner HJ, Knyrim K, Vakil N, Klose KJ. Plastic endoprostheses versus metal stents in the palliative treatment of malignant hilar biliary obstruction. A prospective and randomized trial. Endoscopy 1993;25: 213-218.

32. Kim JH. Endoscopic stent placement in the palliation of malignant biliary obstruction. Clin Endosc 2011;44:76-86.

33. Perdue DG, Freeman ML, DiSario JA, et al. Plastic versus self-expanding metallic stents for malignant hilar biliary obstruction: a prospective multicenter observational cohort study. J Clin Gastroenterol 2008; 42:1040-1046

34. Goenka MK, Goenka U. Palliation: hilar cholangiocarcinoma. World J Hepatol 2014;6:559-569.

35. Kaneko T, Sugimori K, Shimizu Y, et al. Efficacy of plastic stent placement inside bile ducts for the treatment of unresectable malignant hilar obstruction (with videos). J Hepatobiliary Pancreat Sci 2014;21: 349-355.

36. Sangchan A, Chaiyakunapruk N, Supakankunti S, Pugkhem A, Mairiang P. Cost utility analysis of endoscopic biliary stent in unresectable hilar cholangiocarcinoma: decision analytic modeling approach. Hepatogastroenterology 2014;61:1175-1181.

37. Hookey LC, Le Moine O, Deviere J. Use of a temporary plastic stent to facilitate the placement of multiple self-expanding metal stents in malignant biliary hilar strictures. Gastrointest Endosc 2005;62:605-609.

38. Cheng JL, Bruno MJ, Bergman JJ, Rauws EA, Tytgat GN, Huibregtse K. Endoscopic palliation of patients with biliary obstruction caused by nonresectable hilar cholangiocarcinoma: efficacy of self-expandable metallic Wallstents. Gastrointest Endosc 2002;56:33-39.

39. Chennat J, Waxman I. Initial performance profile of a new $6 \mathrm{~F}$ self-expanding metal stent for palliation of malignant hilar biliary obstruction. Gastrointest Endosc 2010;72:632-636.

40. Lee TH, Park do H, Lee SS, et al. Technical feasibility and revision efficacy of the sequential deployment of endoscopic bilateral side-by-side metal stents for malignant hilar biliary strictures: a multicenter prospective study. Dig Dis Sci 2013;58:547-555.

41. Lee JH, Kang DH, Kim JY, et al. Endoscopic bilateral metal stent placement for advanced hilar cholangiocarcinoma: a pilot study of a newly designed Y stent. Gastrointest Endosc 2007;66:364-369.

42. Park do H, Lee SS, Moon JH, et al. Newly designed stent for endoscopic bilateral stent-in-stent placement of metallic stents in patients with malignant hilar biliary strictures: multicenter prospective feasibility study (with videos). Gastrointest Endosc 2009;69:1357-1360.

43. Chahal P, Baron TH. Expandable metal stents for endoscopic bilateral stent-within-stent placement for malignant hilar biliary obstruction. Gastrointest Endosc 2010;71:195-199.

44. Kawamoto H, Tsutsumi K, Fujii M, et al. Endoscopic 3-branched partial stent-in-stent deployment of metallic stents in high-grade malignant hilar biliary stricture (with videos). Gastrointest Endosc 2007;66: 1030-1037.

45. Hwang JC, Kim JH, Lim SG, Kim SS, Yoo BM, Cho SW. Y-shaped endoscopic bilateral metal stent placement for malignant hilar biliary obstruction: prospective long-term study. Scand J Gastroenterol 2011;46: 326-332.

46. Lee TH, Moon JH, Kim JH, et al. Primary and revision efficacy of cross-wired metallic stents for endoscopic bilateral stent-in-stent placement in malignant hilar biliary strictures. Endoscopy 2013;45:106-113.

47. Naitoh I, Nakazawa T, Ban T, et al. 8-mm versus 10 -mm diameter selfexpandable metallic stent in bilateral endoscopic stent-in-stent deployment for malignant hilar biliary obstruction. J Hepatobiliary Pancreat Sci 2015;22:396-401.

48. Naitoh I, Hayashi K, Nakazawa T, et al. Side-by-side versus stent-instent deployment in bilateral endoscopic metal stenting for malignant hilar biliary obstruction. Dig Dis Sci 2012;57:3279-3285.

49. Paik WH, Park YS, Hwang JH, et al. Palliative treatment with self-expandable metallic stents in patients with advanced type III or IV hilar cholangiocarcinoma: a percutaneous versus endoscopic approach. Gastrointest Endosc 2009;69:55-62.

50. Kim CW, Park AW, Won JW, Kim S, Lee JW, Lee SH. T-configured dual stent placement in malignant biliary hilar duct obstructions with a newly designed stent. J Vasc Interv Radiol 2004;15:713-717. 